\title{
Effect of common single nucleotide polymorphisms in COX-1 gene on related metabolic activity in diabetic patients treated with acetylsalicylic acid
}

Marek Postula ${ }^{1,2}$, Piotr K. Janicki ${ }^{3}$, Marek Rosiak ${ }^{1}$, Agnieszka Kaplon-Cieslicka ${ }^{1}$, Agnieszka Kondracka ${ }^{4}$, Ewa Trzepla ${ }^{1}$, Krzysztof J. Filipiak ${ }^{1}$, Dariusz A. Kosior ${ }^{5}$, Andrzej Czlonkowski², Grzegorz Opolski ${ }^{1}$

1Mossakowski Medical Research Centre Polish Academy of Sciences, Warsaw, Poland, 2Department of Noninvasive Cardiology and Hypertension, Central Clinical Hospital, the Ministry of the Interior, Warsaw, Poland

3 Perioperative Genomics Laboratory, Department of Anesthesiology, Penn State College of Medicine, Hershey, Pennsylvania, USA

${ }^{4}$ Department of Internal Medicine and Endocrinology, Medical University of Warsaw, Poland

${ }^{5}$ Department of Noninvasive Cardiology and Hypertension, Central Clinical Hospital, the Ministry of the Interior, Warsaw, Poland

Submitted: 25 February 2012

Accepted: 10 April 2012

Arch Med Sci 2014; 10, 6: 1198-1205

DOI: 10.5114 /aoms.2013.35442

Copyright (c) 2014 Termedia \& Banach

\section{Abstract}

Introduction: The objective of this study was to investigate the effect of common single nucleotide genomic polymorphisms in the cyclooxygenase-1 (COX-1) gene on the thromboxane $A_{2}\left(T_{X A}\right)$ metabolite concentrations in serum and urine, as well as on prostaglandin $\mathrm{F} 2 \alpha$ (PGF2 $\alpha$ ) urinary excretion in the diabetic population on acetylsalicylic acid (ASA) therapy.

Material and methods: The study cohort consisted of 284 Caucasians with diabetes type 2 who had been taking ASA tablets at the dose of $75 \mathrm{mg} /$ day for at least 3 months. Genotyping for the 4 selected SNPs within the COX-1 gene (two nonsynonymous-coding variants, rs3842787 [C50T, P17L] and rs5789 [C174A, L237M]; and two other synonymous SNPs, rs3842788 [G128A, Q41Q] and rs5788 [C644A]) was performed using the Sequenom iPLEX platform.

Results: No statistically significant results were observed for the investigated SNPs and measured metabolites in the investigated cohort of patients. Statistically significant differences in $\mathrm{S}-\mathrm{TXB}_{2}$ could however be observed for rs 5788 in the subgroup of patients with very high $\mathrm{S}-\mathrm{TxB}_{2}$ concentrations. In particular, more patients who were carriers of the minor allele for this polymorphism were observed in the group with $\mathrm{S}-\mathrm{TxB}_{2}$ levels $>95^{\text {th }}$ percentile, when compared with similar carriers in the group with $\mathrm{S}-\mathrm{TxB}_{2}<95^{\text {th }}$ percentile $(20 \% \mathrm{vs} .1 .1 \%$, respectively, $p<0.001$, Mann-Whitney test).

Conclusions: The results of our study suggest that the four investigated common SNPs in the COX1 gene are not associated with obviously altered $\mathrm{TXA}_{2}$ metabolism and PGF2 $\alpha$ synthesis in the investigated diabetic cohort treated with ASA.

Key words: acetylsalicylic acid, cyclooxygenase-1, diabetes mellitus, thromboxane, 8-iso-prostaglandin F2 $\alpha$.

\section{Introduction}

Several mechanisms caused by metabolic and cellular abnormalities have been suggested to play a role in increased platelet reactivity. Endogenous

\author{
Corresponding author: \\ Marek Rosiak \\ Department of Cardiology \\ Medical University of Warsaw \\ 1 A Banacha St \\ 02-097 Warsaw, Poland \\ Phone: +48225991958 \\ Fax: +48 225991957 \\ E-mail: \\ marek.rosiak@gmail.com
}


and environmental factors - age, cholesterol and inflammatory markers levels, hypertension, diabetes mellitus, and cigarette smoking - explain only part of the variation in platelet function observed in persons with these conditions [1-9]. Although inherited and genetic factors have known links to cardiovascular disease, the evidence for genetic influences that enhance platelet function is much weaker [10-12].

Patients with type 2 diabetes mellitus (T2DM) are characterized by an elevated risk of recurrent atherothrombotic events. In addition, acetylsalicylic acid (ASA) therapy may be less effective in high-risk populations [11, 13, 14]. Patients with T2DM exhibit platelet hyperreactivity both in vitro and in vivo coupled with biochemical evidence of persistently increased thromboxane-dependent platelet activation [3-6]. Furthermore, polymorphisms in different genes have been associated with variability for increased platelet reactivity on ASA therapy in T2DM patients [14-16].

The problems with determining ASA response and the different methodologies available for determining the biochemical and functional effects of ASA have compounded the problems of attempting to define increased platelet reactivity despite ASA therapy, with some investigators suggesting that the term should be used only when production of thromboxane $A_{2}\left(T_{x} A_{2}\right)$ (or its breakdown products) is blocked regardless of platelet function $[11,17]$.

Acetylsalicylic acid irreversibly inhibits cyclooxygenase (COX)-1 in human platelets. COX-1 (prostaglandin endoperoxide $\mathrm{G} / \mathrm{H}$ synthase) catalyzes the formation of prostaglandin $\mathrm{H}_{2}\left(\mathrm{PGH}_{2}\right)$ from arachidonic acid (AA). This action is the committed step in prostaglandin synthesis, which yields the bioactive eicosanoids, prostaglandin D2, prostaglandin F2 $\alpha$ (PGF2 $\alpha$ ), prostaglandin $\mathrm{I}_{2}$, and TxA 2 through branching enzymatic pathways (Figure 1) [18]. The effect of ASA repeatedly administered once daily is irreversible, cumulative and saturable, reaching a ceiling effect in the low dose range [19]. The TxA production can be determined by measuring stable metabolites of $T x A_{2}$, such as thromboxane $B_{2}\left(T x B_{2}\right)$ in the serum and 11-dehydro- $T \times B_{2}$ (11-dh- $\left.T x B_{2}\right)$ in the urine. Because serum $\mathrm{TxB}_{2}$ production is predominantly dependent on platelet COX-1, it has been used as a primary measure of the inhibitory effects of low-dose ASA on platelets [20]. In addition to $T X A_{2}$, platelets release $F 2$-isoprostanes, in particular 8 -iso-prostaglandin F2 $\alpha$ (8-iso-PGF2 $\alpha$ ), a chemically stable compound derived from enzymatic and nonenzymatic oxidation of AA [21]. Platelet 8 -iso-PGF2 $\alpha$ is synthesized in vivo as a minor product of the COX-1 enzyme in human platelets and the COX-2 isoform in human monocytes, as well as through the free radical-catalyzed peroxidation of AA in biological membranes $[22,23]$. Because 8 -iso-PGF2 $\alpha$ formation might correlate with the rate of $\mathrm{TxA}_{2}$ biosynthesis, it was hypothesized that increased oxidant stress in T2DM could induce enhanced generation of 8-iso-PGF2 $\alpha$, which can contribute to platelet activation [24]. Even if it was demonstrated previously that enhanced 8-isoPGF2 $\alpha$ synthesis may be associated with advanced age, cigarette smoking, hypercholesterolemia, and unstable angina, as well as after coronary artery reperfusion, the role of 8-iso-PGF2 $\alpha$ in ASA's effect on $\mathrm{TXA}_{2}$ synthesis remains uncertain [25-33].

Genetic variation in COX-1 may affect enzyme expression, biochemical function or interaction with pharmacological agents [21]. The gene encoding human COX-1 (PTGS1), mapped to chromosome 9q32-q33.3, is approximately $22 \mathrm{~kb}$ in length, and contains 11 exons [22, 34]. COX-1 is constitutively expressed and is responsible for the biosynthesis of PGs involved in various functions, such as the regulation of renal, gastrointestinal, and platelet activity [18]. Several single nucleotide polymorphisms (SNPS) in both coding and noncoding regions of human COX-1 have been previously identified and were postulated to change its activity; however, all these studies were performed in healthy individuals or in patients with coronary

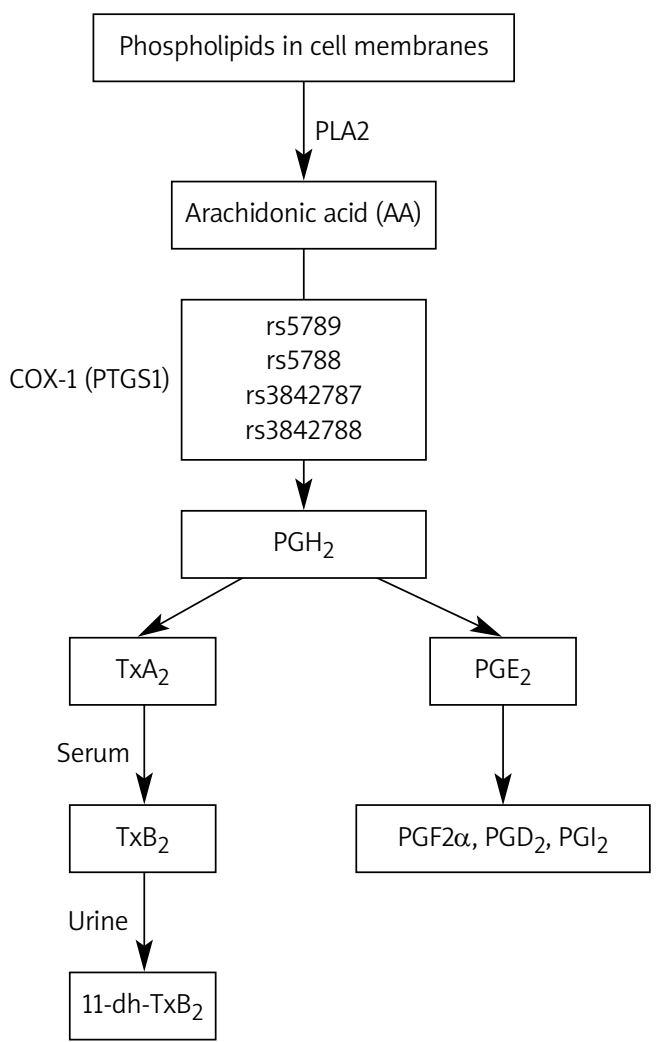

Figure 1. Arachidonic acid cascade and investigated single nucleotide polymorphisms (SNPs)

PLA2 - phospholipase A2, COX-1 - cyclooxygenase-1, $P G H_{2}$ - prostaglandin $\mathrm{H}_{2}, P G F 2 \alpha$ - prostaglandin $F 2 \alpha, P G D_{2}-$ prostaglandin $D_{2}, P G J_{2}$ - prostaglandin $\mathrm{J}_{2}, T \times A_{2}$ - thromboxane $A_{2}, T \times B_{2}$ - thromboxane $B_{2}, 11-d h-T x B_{2}-11$-dehydro- $T \times B_{2}$ 
artery disease (CAD) [11, 12, 35-37]. In addition, there is no systemic information published about the effects of these common SNPs on the function of COX-1, as measured directly by $\mathrm{TXA}_{2}$ metabolites and 8-iso-PGF2 $\alpha$ concentrations in the diabetic population. To our knowledge, there is also no information about the effects of these common SNPs in the COX-1 gene on the related metabolic activity in the Polish population.

Thus, the objective of this study was to evaluate the impact of the four frequently investigated COX-1 gene polymorphisms in the entirely diabetic population on ASA therapy on $\mathrm{TxA}_{2}$ synthesis, measured as serum and urinary $\operatorname{TxA}_{2}$ metabolite concentrations, as well as on 8-iso-PGF2 $\alpha$ synthesis measured as its urinary excretion. The genotyping was attempted for four COX-1 SNPs (two missense variants, rs3842787 [C50T, P17L] and rs5789 [C174A, L237M]; and two other synonymous SNPs, rs3842788 [G128A, Q41Q] and rs5788 [C644A]).

\section{Material and methods}

\section{Patient population and study design}

The ethics committee of the Medical University of Warsaw approved both the study protocol and the informed consent form. The study was conducted in accordance with the current version of the Declaration of Helsinki at the time when the study was designed, and informed written consent was obtained. The genotyping part of the study was reviewed and approved by the Institutional Review Board of Penn State Hershey Medical Center (Hershey, PA, USA). The study subjects were recruited consecutively from patients with T2DM participating in the multi-center, prospective, randomized, and open-label AVOCADO (Aspirin Vs/Or Clopidogrel in Aspirin-resistant Diabetics inflammation Outcomes) study presenting to the outpatient clinic of the Central Teaching Hospital of the Medical University of Warsaw. The full characteristics of the study population, including the inclusion and exclusion criteria, were published previously [14, 38]. Briefly, the study recruited 304 subjects with T2DM who, at the time of enrollment, had been taking ASA tablets at the dose of $75 \mathrm{mg}$ per day for at least 3 months for primary or secondary prevention of myocardial infarction (MI). No clopidogrel or antiplatelet drugs other than ASA were used in any of the investigated patients. All patients had been taking oral antidiabetic agents and/or insulin for at least 6 months; diet-controlled diabetic patients were not included. Compliance with ASA therapy was determined at the study entry based upon the patient's own statement and serum thromboxane $\mathrm{B}_{2}\left(\mathrm{~S}-\mathrm{TxB}_{2}\right)$ levels below $7.2 \mathrm{ng} / \mathrm{ml}$ in all patients as described previously in a diabetic population by Mortensen et al. [6].

\section{Blood sample and assay procedures}

Blood samples were taken in the morning 2-3 $\mathrm{h}$ after the last ASA dose. Blood was taken from the antecubital vein, and the initial $2 \mathrm{ml}$ of blood were discarded to avoid spontaneous platelet activation. Whole blood for $\mathrm{S}-\mathrm{TxB}_{2}$ was allowed to clot at $37^{\circ} \mathrm{C}$ for $1 \mathrm{~h}$ before separating serum by centrifugation. Serum was obtained from venous blood by centrifugation at $1000 \mathrm{~g}$ for $15 \mathrm{~min}$ at $4^{\circ} \mathrm{C}$, and aliquots were stored at $-80^{\circ} \mathrm{C}$ for further analysis. Regular laboratory testing was performed at the laboratory of the Central Teaching Hospital, Medical University of Warsaw, using standard techniques, and included complete blood cell and platelet counts, fasting glycemia, glycosylated hemoglobin $\left(\mathrm{HbA}_{1 c}\right)$, lipid profile, $\mathrm{C}$-reactive protein and serum creatinine concentrations.

\section{Urinary 11-dehydro-thromboxane $B_{2}$ $\left(11-d h-T_{x} B_{2}\right)$}

11-dh- $\mathrm{TxB}_{2}$ was measured using an enzyme immunoassay kit according to the manufacturer's instructions (EIA kit, Cayman Chemical) after extraction and purification on SPE (C18) columns (Waters Associates, Milford, MA, USA). Data were normalized for urinary creatinine concentration.

\section{Serum thromboxane $\mathrm{B}_{2}\left(\mathrm{~S}-\mathrm{Tx}_{2}\right)$}

$\mathrm{S}-\mathrm{TxB}_{2}$ was measured also with an enzyme immunoassay kit according to the manufacturer's instructions (Cayman Chemicals, Ann Arbor, MI, USA). Each lot of $\mathrm{TxB}_{2}$ EIA kit was tested for the impact of interferences. The correlation of results in three dilutions of five random samples was assessed, as was proposed in the kit protocol. The decision to use the assay without purification was taken after analysis of results, as differences of results did not exceed $20 \%$. Samples with results outside the standard curve were re-assayed with appropriate dilutions.

\section{Urinary isoprostane measurement}

Quantification of 8-iso-PGF2 $\alpha$ was performed on a morning urine sample with an enzyme immunoassay kit (8-isoprostane EIA Kit, Cayman Chemical, Ann Arbor, MI, USA) and normalized to urinary creatinine concentration.

\section{DNA extraction, quality control, and quantification}

DNA was obtained from whole blood samples by the membrane ultrafiltration method using a Fuji MiniGene 80 extractor (FujiFilm Life Sciences distributed by Autogene, Holliston, MA), as described previously $[15,16]$. 


\section{Individual SNP genotyping}

Genotyping was performed at Boston Children's Hospital using a custom Sequenom iPLEX assay in conjunction with the Mass ARRAY platform (Sequenom Inc., La Jolla, CA, USA). One panel of SNP markers was designed using Sequenom Assay Design 3.2 software.

\section{Statistical analysis}

\section{Power analysis}

We planned a prospective, observational study of diabetic patients treated with ASA. The required sample size $(n=265)$ of the study was designed to have a power of $>80 \%$ to detect a change in $\mathrm{S}-\mathrm{TxB}_{2}$ level corresponding to a significant 2-fold increase in $\mathrm{S}-\mathrm{TxB}_{2}$ concentration between alleles of the 4 investigated SNPs at a 0.05/4 $=0.0125$ level of significance, with Bonferroni correction applied.

\section{Statistical calculations}

The statistical analyses were performed using IBM-SPSS ver. 19 and Stata (Stata Corporation, College Station, TX) software. Deviations from HardyWeinberg equilibrium (HWE) were calculated using the $\chi^{2}$ test. The recorded clinical data, when normally distributed in the analyzed group of patients, are presented as mean and SD, and non-normally distributed data are presented as medians and interquartile range (IQR). In the first stage of the analysis we compared the distribution of median S-TxB, $11-d h-\mathrm{TxB}_{2}$ and 8-iso-PGF2 $\alpha$ levels among all genotypes of successfully genotyped SNPs using the Kruskal-Wallis test. The SNPs with nominal statistically significant (i.e. $p<0.05$ before applying correction for multiple comparisons) differences in the measurements $\left(\mathrm{S}-\mathrm{TxB}_{2}, 11-\mathrm{dh}-\mathrm{TxB}_{2}\right.$ and 8-isoPGF2 $\alpha$ levels) between medians for each of three genotypes (i.e., homozygotes for minor allele, heterozygotes and homozygotes for major allele) were subjected to further testing based on the dominant, recessive or additive genetic model by MannWhitney test.

\section{Results}

From the initially enrolled 304 patients, complete clinical data and blood samples finally became available for 298 patients. Subsequently, 8 patients were eliminated from the analysis based on the suspected ASA non-compliance (patients' own statement and $\mathrm{S}-\mathrm{TxB}_{2}$ concentrations $>7.2 \mathrm{ng} / \mathrm{ml}$ ) and a further 6 patients were eliminated because of the lack of corresponding biochemical and genotype data. Demographic characteristics and clinical data for the remaining 284 patients are summarized in Table I.

The summary results of the allele and genotype frequencies for all genotyped SNPs are summarized in Table II. All 4 SNPs genotyped well (> $86 \%$ success rate) and were in Hardy-Weinberg equilibrium. For each of the successfully genotyped SNPs, we initially compared the corresponding $\mathrm{S}-\mathrm{Tx}_{2}$, and urine 11-dh-TxB ${ }_{2}$ and 8-iso-PGF2 $\alpha$ excretion data between 3 allelic groups (e.g. homozygotes for minor and major alleles, as well as heterozygotes) using the non-parametric Kruskal-Wallis test. The obtained results did not reveal any statistically significant differences in $\mathrm{S}-\mathrm{TxB}_{2}, 11-\mathrm{dh}-\mathrm{TxB}_{2}$ and 8-isoPGF2 $\alpha$ concentrations for carriers and non-carriers of the investigated SNP variants.

Table I. Demographic and clinical characteristics of the study patients $(n=284)$

\begin{tabular}{|c|c|}
\hline \multicolumn{2}{|c|}{ Demographics } \\
\hline Age [years] & $67.6 \pm 8.7$ \\
\hline Female, $n(\%)$ & $135(47.5)$ \\
\hline $\mathrm{BMI}\left[\mathrm{kg} / \mathrm{m}^{2}\right]$ & $31.19 \pm 12.0$ \\
\hline $\mathrm{SBP}[\mathrm{mm} \mathrm{Hg}]$ & $142.3 \pm 18.9$ \\
\hline $\mathrm{DBP}[\mathrm{mm} \mathrm{Hg}]$ & $80.5 \pm 11.3$ \\
\hline Dyslipidemia & $234(82.4 \%)$ \\
\hline Hypertension & $262(92.3 \%)$ \\
\hline CAD & $162(57.0 \%)$ \\
\hline Prior MI & 87 (30.6\%) \\
\hline Prior stroke & $23(8.1 \%)$ \\
\hline Heart failure & 107 (37.7\%) \\
\hline History of smoking & $160(56.3 \%)$ \\
\hline Current smoking & $28(9.8 \%)$ \\
\hline \multicolumn{2}{|c|}{ Concurrent medications } \\
\hline Oral hypoglycemic & $243(85.6 \%)$ \\
\hline Insulin & 93 (32.7\%) \\
\hline$\beta$-Blockers & $205(72.2 \%)$ \\
\hline ACE inhibitors & $185(65.1 \%)$ \\
\hline Statins & $206(72.6 \%)$ \\
\hline \multicolumn{2}{|c|}{ Biochemical and hematological parameters } \\
\hline $\mathrm{HGB}[\mathrm{g} / \mathrm{dl}]$ & $13.8 \pm 1.3$ \\
\hline $\mathrm{HCT}[\%]$ & $41.3 \pm 4.5$ \\
\hline WBC $\left[10^{3} / \mathrm{mm}^{3}\right]$ & $7.1 \pm 2.2$ \\
\hline $\mathrm{PLT}\left[10^{3} / \mathrm{mm}^{3}\right]$ & $227.8 \pm 58.3$ \\
\hline MPV [fl] & $9.9 \pm 1.2$ \\
\hline $\mathrm{eGFR}[\mathrm{ml} / \mathrm{min} / 1.73]$ & $70.8 \pm 20.9$ \\
\hline $\mathrm{HbA}_{1 \mathrm{c}}[\%]$ & $7.0 \pm 1.3$ \\
\hline hsCRP & $4.1 \pm 5.6$ \\
\hline
\end{tabular}

Data are presented as mean $\pm S D$ unless otherwise indicated. $B M I$ - body mass index, SBP - systolic blood pressure, DBP - diastolic blood pressure, $C A D$ - coronary artery disease, $M I-$ myocardial infarction, $A C E$ - angiotensin-converting enzyme, HGB - hemoglobin, $H C T$ - hematocrit, WBC - white blood cells, PLT - platelet count, MPV - mean platelet volume, eGFR - estimated glomerular filtration rate, $H b A_{1 c}$ - glycosylated hemoglobin, hSCRP - high-sensitivity C-reactive protein. 
Table II. The effects of different analyzed genotypes of SNPS in COX-1 on plasma levels of S-TxB2 and urine excretion of 11-dh-TxB 2 and 8-iso-PGF2 $\alpha$ in diabetic patients on ASA

\begin{tabular}{|c|c|c|c|}
\hline Analyzed SNPs in COX-1 & $\begin{array}{l}\text { S-TxB } \\
{[\mathrm{ng} / \mathrm{ml}]}\end{array}$ & $\begin{array}{c}\text { 11-dh-TxB } 2 \\
{[\mathrm{ng} / \mathrm{mmol} \mathrm{Cr}]}\end{array}$ & $\begin{array}{r}\text { 8-iso-PGF2 } \alpha \\
{[\mathrm{ng} / \mathrm{mg} \mathrm{Cr}]}\end{array}$ \\
\hline \multicolumn{4}{|c|}{ Rs5788 C>A (MAF $=0.180)$} \\
\hline Homozygotes for major allele $(n=193)$ & $0.155(0.6)$ & $40.485(40.82)$ & $0.411(0.3)$ \\
\hline Heterozygotes $(n=81)$ & $0.159(0.6)$ & $38.990(41.55)$ & $0.410(0.4)$ \\
\hline Homozygotes for minor (variant) allele $(n=10)$ & $0.107(1.7)$ & $61.690(108.70)$ & $0.405(0.2)$ \\
\hline$P^{*}(\mathrm{KW}$ test $)$ & 0.945 & 0.288 & 0.885 \\
\hline \multicolumn{4}{|c|}{ Rs5789 C>A (MAF = 0.017) } \\
\hline Homozygotes for major allele $(n=275)$ & $0.153(0.6)$ & $40.490(41.56)$ & $0.410(0.3)$ \\
\hline Heterozygotes $(n=8)$ & $0.223(0.5)$ & $26.200(38.89)$ & $0.352(0.5)$ \\
\hline Homozygotes for minor (variant) allele $(n=1)$ & $\mathrm{n} / \mathrm{a}$ & $\mathrm{n} / \mathrm{a}$ & $\mathrm{n} / \mathrm{a}$ \\
\hline $\mathrm{P}(\mathrm{MW}$ test $)$ & 0.509 & 0.247 & 0.597 \\
\hline \multicolumn{4}{|c|}{ Rs3842787 C>T (MAF = 0.061) } \\
\hline Homozygotes for major allele $(n=250)$ & $0.154(0.6)$ & $40.430(41.68)$ & $0.406(0.3)$ \\
\hline Heterozygotes $(n=28)$ & $0.157(0.6)$ & $42.800(42.07)$ & $0.494(0.4)$ \\
\hline Homozygotes for minor (variant) allele $(n=3)$ & $0.033(-)$ & $36.980(-)$ & $0.301(-)$ \\
\hline $\mathrm{P}$ (MW test) & 0.602 & 0.978 & 0.284 \\
\hline \multicolumn{4}{|c|}{ Rs3842788 G>A (MAF $=0.015)$} \\
\hline Homozygotes for major allele $(n=275)$ & $0.154(0.5)$ & $40.450(40.45)$ & $0.410(0.3)$ \\
\hline Heterozygotes $(n=9)$ & $0.071(1.1)$ & $39.505(57.38)$ & $0.342(0.4)$ \\
\hline Homozygotes for minor (variant) allele $(n=0)$ & $\mathrm{n} / \mathrm{a}$ & $\mathrm{n} / \mathrm{a}$ & $\mathrm{n} / \mathrm{a}$ \\
\hline P (MW test) & 0.815 & 0.897 & 0.945 \\
\hline
\end{tabular}

Data are shown as median and interquartile range (IQR). ${ }^{\star} P$ using Kruskal-Wallis (KW) test for differences between 3 analyzed genotypes for each SNP or using Mann-Whitney test (MW) for differences between 2 genotypes (carriers of wild-type allele and pooled carriers of variant allele); $n$ - number of carriers for each genotype, MAF - minor allele frequency for each analyzed SNP in investigated cohort, SNPS - single nucleotide polymorphisms, COX-1 - cyclooxygenase-1, S-TX $B_{2}$ - serum thromboxane $B_{2}$, 11-dh-TxB $B_{2}$ - urinary 11-dehydro-thromboxane $B_{2}$, 8-iso-PGF2 $\alpha$ 8-iso-prostaglandin $F 2 \alpha$.

In order to more closely analyze the relationship between $\mathrm{S}-\mathrm{TXB}_{2}$ and $\mathrm{COX}-1$ polymorphisms (in particular in the outlier sub-cohort with $\mathrm{S}-\mathrm{TxB}_{2}>75^{\text {th }}$ percentile), we also established several empirical cut-off criteria (e.g., at $75^{\text {th }}$ percentile $0.612 \mathrm{ng} / \mathrm{ml}$, $1.5 \times 75^{\text {th }}$ percentile $0.918 \mathrm{ng} / \mathrm{ml}$, and at $95^{\text {th }}$ percentile $4.05 \mathrm{ng} / \mathrm{ml}$ ), which divided the investigated patients into 2 categories, based on S-TxB $\mathrm{B}_{2}$ concentration. No effects of any investigated polymorphisms in COX-1 were observed for the analyzed patient cohort with the S-TxB 2 cut-off at the $75^{\text {th }}$ percentile or $1.5 \times 75^{\text {th }}$ percentile (not shown). When the investigated cohort was subsequently divided into two parts, based on the $95^{\text {th }}$ percentile, a statistically significant difference could be established for the rs5788 polymorphism, based on the recessive model, i.e., in carriers of a variant minor allele. In particular, more patients who were carriers of the minor allele for this polymorphism were observed in the group with $\mathrm{S}-\mathrm{TxB}_{2}$ levels $>95^{\text {th }}$ percentile, when compared with similar carriers in the group with $\mathrm{S}-\mathrm{TxB}_{2}<95^{\text {th }}$ percentile $(20 \%$ vs. $1.1 \%$, respectively, $p<0.001$, Mann-Whitney test). No changes were observed for the analyzed outliers in S-TxB $2,11-d h-\mathrm{TxB}_{2}$ or 8-iso-PGF2 $\alpha$ or for the other three investigated SNPs in COX-1.

The presented statistical analysis was performed on 284 patients with observed $\mathrm{S}-\mathrm{TxB}_{2}$ levels above the non-compliance threshold (i.e. S- $\mathrm{TxB}_{2}>7.2 \mathrm{ng} /$ $\mathrm{ml})$. Very similar results were obtained when this analysis was repeated in all 292 patients (i.e. without removal of any of them for suspected non-compliance), including the effect of rs5788 polymorphism on outlier S-TxB 2 levels (data not shown).

\section{Discussion}

The current genetic study of platelet reactivity during chronic ASA therapy represents, to our knowledge, the first comprehensive analysis of SNPs in the COX-1 gene during chronic ASA therapy in diabetic patients and aims to directly correlate genetic variants within the $C O X-1$ gene with AA metabolites (i.e. $\mathrm{TxB}_{2}$, 11-dehydro $\mathrm{TxB}_{2}$, 8-isoPGF2 $\alpha$ ) in an ethnically homogeneous and entire- 
ly diabetic population from central Poland. In our study COX-1 inhibition was based on $\mathrm{TxA}_{2}$-related measurements, such as serum $\mathrm{TxB}_{2}$ levels (index of the maximum biosynthetic capacity of platelet COX-1 ex vivo) and urinary 11-dehydro $\mathrm{TxB}_{2}$ excretion (index of in vivo TxA 2 biosynthesis) $[39,40]$.

We found that four common COX-1 gene polymorphisms (two missense variants, rs3842787 [C50T, P17L] and rs5789 [C174A, L237M]; and two other synonymous SNPs, rs3842788 [G128A, Q41Q] and rs5788 [C644A]) (Table II) had no statistically significant effects on $\mathrm{TxA}_{2}$-related indexes and 8 -iso-PGF2 $\alpha$ excretion in the investigated diabetic patients treated with ASA. A possible exception was observed for SNP rs5788, for which the carriers of the minor allele for this polymorphism were more frequently observed in the group with $\mathrm{S}-\mathrm{Tx}_{2}$ levels $>95^{\text {th }}$ percentile, when compared with similar carriers in the group with $\mathrm{S}-\mathrm{TxB}_{2}<95^{\text {th }}$ percentile ( $20 \%$ vs. $1.1 \%$, respectively, $p<0.001$, Mann-Whitney test). The clinical significance of this last finding remains unclear, but may indicate that this SNP could be responsible for the inter-individual differences in the $\mathrm{S}-\mathrm{TxB}_{2}$ concentrations in at least a small portion of the patients with high COX-1 activity or may be due to known or unknown genetic variants in linkage disequilibrium.

Several genetic variants in human COX-1 were found previously to alter COX-1-mediated AA metabolism in the non-diabetic population; however, only the rs3842787 (or so-called C50T) polymorphism in COX-1 was repeatedly shown to be of functional significance in relation to the antiplatelet effect of ASA $[11,12,41,42]$. Some studies demonstrated an association between this SNP and reduced ASA effect on platelet aggregation and $\mathrm{Tx}_{2}$ formation [21, 43, 44]. Gonzalez-Conejero et al. demonstrated that ASA-treated healthy subjects with the COX-1 rs3842787 polymorphism had an almost two-fold increase in-vivo $\mathrm{TxB}_{2}$ production [43]. Similar findings were observed in a trial including 144 patients with stable CAD, which showed higher AA-induced platelet aggregation and serum $\mathrm{Tx}_{2}$ synthesis in carriers with a haplotype containing the variant of rs3842787 [21]. Lepantalo et al. examined the polymorphisms of COX-1 on antiplatelet effect of ASA in coronary artery disease patients and observed a correlation with $A A$-induced aggregometry and PFA100 , but not with serum $\mathrm{TxB}_{2}$ levels [44]. However, a recent comprehensive systematic review revealed no significant association of rs3842787 with socalled "ASA resistance", as the number of studies and of subjects used was small, making it difficult to exclude definitively any contribution of these polymorphisms to the effect of ASA (OR for aspirin resistance 1.07; 95\% $\mathrm{Cl} 0.41,2.77 ; p=0.89$ ) [11].

Platelet 8 -iso-PGF2 $\alpha$ is synthesized in vivo as a minor product of the COX-1 enzyme in human platelets and the COX-2 isoform in human monocytes and mostly independently of the activity of COX-1, through the free radical- catalyzed peroxidation of $A A$ in biological membranes [22, 23]. Contrary to $\mathrm{TxA}_{2}$, 8-iso-PGF2 $\alpha$ does not directly induce platelet aggregation, but it elicits shape change, amplifies the platelet response to common agonists, and enhances platelet recruitment, and thus can modulate platelet aggregation through the thromboxane receptor (TP) or a closely related receptor, regardless of COX-1 inhibition by ASA [23, 24, 32]. As thromboxane synthase inhibitors do not reliably inhibit $A A$-induced platelet aggregation, it was postulated that the measurement of 8-isoPGF2 $\alpha$ can serve as a better marker than $\mathrm{TxB}_{2}$ for analysis of the correlation between functional outcomes and genetic variants at the COX-1 locus. Because platelet COX activity can also produce small (when compared with $\mathrm{TxB}_{2}$ ) amounts of 8 -iso-PGF2 $\alpha$, we tried to establish an association between enhanced urinary excretion of 8 -iso-PGF2 $\alpha$ and COX-1 polymorphisms that could influence its enzymatic activity. Halushka et al. reported that ASA has an enhanced inhibitory effect on in vitro $\mathrm{PGH} 2$ formation by platelets (measured as 8-iso-PGF2 $\alpha$ ) from healthy carriers of variant allele rs3842787 [35]. In contrast to those results, we did not find any association between rs3842787 (C50T) SNP and 8 -iso-PGF2 $\alpha$ levels in the diabetic population. These differences could be, in part, explained by the previous report that compared 8 -iso-PGF2 $\alpha$ excretion in the presence and absence of platelet COX blockade by low-dose aspirin. In this study COX-1 inhibition, as reflected by suppression of $\mathrm{TxB}_{2}$ biosynthesis, was not associated with any detectable difference in $\mathrm{F}_{2}$-isoprostane formation [32]. In another study it was also shown that urinary 8-isoPGF2 $\alpha$ excretion did not contribute to impaired platelet responsiveness to ASA in a COX-1 dependent mechanism [33].

According to Lee et al., the COX-1 rs5789 (L237M) variant can presumably influence catalytic activity of COX-1 through its predicted impact on dimerization [42]. Moreover, they found that COX-1 metabolic activity in vitro was significantly lower with the rs5789 (L237M) variant relative to wild type after inhibition with indomethacin as the carriers of the rs5789 (L237M) variant also had significantly lower basal activity [42]. However, this observation may not extend to all NSAIDs, and thus TxB2 formation on ASA therapy in vivo.

The inherent limitations of observational design apply to this study. The candidate SNPs within the COX-1 gene were chosen because of their established or suspected influence on platelet function, as assessed by numerous studies in several laboratories. However, it cannot be ruled out that some other non-analyzed SNPs (or other genetic variants) 
can alter COX-1 activity. As such, our current findings should be interpreted with caution and await further confirmation from more detailed studies. Moreover, pretreatment measurements (i.e. before beginning ASA treatment) could not be conducted because all patients included in this study had diagnosed $C A D$ or multiple risk factors for $C A D$ and therefore were on ASA therapy at the time of enrollment. Other weaknesses of our study include the lack of external replication in an independent cohort of diabetic patients. Lastly, our association might be either random or associated with the particular patient population (e.g. diabetes), and this question could not be answered in this study.

In conclusion, we were unable to confirm an association between investigated common COX-1 gene SNPS and COX-1 activity in the diabetic population treated with a low dose of ASA. Additional investigation is warranted to establish whether COX-1 activity in the T2DM population may be influenced by other, less frequent, genetic variants of COX-1, which were not investigated in this study. Further studies in larger and different ethnic diabetic populations are needed to validate and possibly extend the conclusions from this relatively small, but ethnically homogeneous, cohort.

\section{Acknowledgments}

Marek Postula and Piotr K. Janicki contributed equally to this work.

Dr Postula was supported by a Fulbright Fellowship. The authors thank Thutrang Nguyen, B.A. (Laboratory Manager), from the SNP Genotyping Core Facility at Boston Children's Hospital, Massachusetts, for performing the custom Sequenom iPLEX assay. The authors alone are responsible for the content and writing of this paper.

The AVOCADO study was supported financially as part of a research grant from the Polish Pharmaceutical Company ADAMED for a Young Scientist 2007 Award grant number: 1WR DAR1/2007.

\section{References}

1. Patrono C, Rocca B. Aspirin: promise and resistance in the new millennium. Arterioscler Thromb Vasc Biol 2008; 28: 25-32.

2. Boncler M, Gresner P, Nocun M, et al. Elevated cholesterol reduces acetylsalicylic acid-mediated platelet acetylation. Biochim Biophys Acta 2007; 1770: 1651-9.

3. Ferroni P, Basili S, Falco A, Davi G. Platelet activation in type 2 diabetes mellitus. J Thromb Haemost 2004; 2 : 1282-91.

4. DiChiara J, Bliden KP, Tantry US, et al. The effect of aspirin dosing on platelet function in diabetic and nondiabetic patients: an analysis from the aspirin-induced platelet effect (ASPECT) study. Diabetes 2007; 56: 3014-9.

5. Evangelista V, de Berardis G, Totani L, et al. Persistent platelet activation in patients with type 2 diabetes treated with low doses of aspirin. J Thromb Haemost 2007; 5: 2197-203.

6. Mortensen SB, Larsen SB, Grove EL, Kristensen SD, Hvas AM. Reduced platelet response to aspirin in patients with coronary artery disease and type 2 diabetes mellitus. Thromb Res 2010; 126: e318-22.

7. Suwalski G, Suwalski P, Filipiak KJ, et al. The effect of offpump coronary artery bypass grafting on platelet activation in patients on aspirin therapy until surgery day. Eur J Cardiothorac Surg 2008; 34: 365-9.

8. Postuła M, Tarchalska-Kryńska B, Filipiak KJ, et al. Factors responsible for "aspirin resistance" - can we identify them? Kardiol Pol 2010; 68: 403-11.

9. Rosiak M, Postula M, Kaplon-Cieslicka A, et al. Effect of ASA dose doubling versus switching to clopidogrel on plasma inflammatory markers concentration in patients with type 2 diabetes and high platelet reactivity: the AVOCADO study. Cardiol J 2013 in press, DOI: 10.5603/ CJ.2013.0045.

10. Gluba A, Banach M, Mikhailidis DP, Rysz J. Genetic determinants of cardiovascular disease: the renin-angiotensin-aldosterone system, paraoxonases, endothelin-1, nitric oxide synthase and adrenergic receptors. In Vivo 2009; 23: 797-812.

11. Goodman T, Ferro A, Sharma P. Pharmacogenetics of aspirin resistance: a comprehensive systematic review. $\mathrm{Br}$ J Clin Pharmacol 2008; 66: 222-32.

12. Würtz M, Kristensen SD, Hvas AM, Grove EL. Pharmacogenetics of the antiplatelet effect of aspirin. Curr Pharm Des 2012; 18: 5294-308.

13. Catakoglu AB, Aytekin S, Celebi H, et al. The influence of aspirin resistance on non-fatal coronary events following percutaneous coronary interventions. Arch Med Sci 2009; 5: 531-8.

14. Baigent C, Sudlow C, Collins R, et al. Collaborative metaanalysis of randomised trials of antiplatelet therapy for prevention of death, myocardial infarction, and stroke in high risk patients. BMJ 2002; 324: 71-86.

15. Postula M, Kaplon-Cieslicka A, Rosiak M, et al. Genetic determinants of platelet reactivity during acetylsalicylic acid therapy in diabetic patients: evaluation of 27 polymorphisms within candidate genes. J Thromb Haemost 2011; 9: 2291-301.

16. Postula M, Janicki PK, Rosiak $M$, et al. New single nucleotide polymorphisms associated with differences in platelets reactivity in patients with type 2 diabetes treated with acetylsalicylic acid: genome-wide association approach and pooled DNA strategy. J Thromb Thrombolysis 2012 Epub ahead of print.

17. Gasparyan AY. Aspirin resistance: more emphasis on definition and appropriate use of platelet function tests is needed. Arch Med Sci 2009; 5: 539-41.

18. Smith WL, Garavito RM, DeWitt DL. Prostaglandin endoperoxide $\mathrm{H}$ synthases (cyclooxygenases)-1 and -2. J Biol Chem 1996; 271: 33157-60.

19. Patrono C, Ciabattoni G, Patrignani P, et al. Clinical pharmacology of platelet cyclooxygenase inhibition. Circulation 1985; 72: 1177-84.

20. Krasopoulos G, Brister SJ, Beattie WS, Buchanan MR. Aspirin "resistance" and risk of cardiovascular morbidity: systematic review and meta-analysis. BMJ 2008; 336: 195-8.

21. Maree AO, Curtin RJ, Chubb A, et al. Cyclooxygenase-1 haplotype modulates platelet response to aspirin. J Thromb Haemost 2005; 3: 2340-5.

22. Yokoyama C, Tanabe T. Cloning of human gene encoding prostaglandin endoperoxide synthase and primary 
structure of the enzyme. Biochem Biophys Res Commun 1989; 165: 888-94.

23. Praticò D, Lawson JA, FitzGerald GA. Cyclooxygenasedependent formation of the isoprostane 8-epi-prostaglandin F2alpha. J Biol Chem 1995; 270: 9800-8.

24. Davì $G$, Ciabattoni $G$, Consoli $A$, et al. In vivo formation of 8-iso-prostaglandin F2alpha and platelet activation in diabetes mellitus: effects of improved metabolic control and vitamin E supplementation. Circulation 1999; 99: 224-9.

25. Wang Z, Ciabattoni G, Crèminon C, et al. Immunological characterization of urinary 8-epi-PGF2alpha excretion in man. J Pharmacol Exp Ther 1995; 275: 94-100.

26. Morrow JD, Frei B, Longmire AW, et al. Increase in circulating products of lipid peroxidation (F2-isoprostanes) in smokers: smoking as a cause of oxidative damage. N Engl J Med 1995; 332: 1198-203.

27. Reilly M, Delanty N, Lawson JA, et al. Modulation of oxidant stress in vivo in chronic cigarette smokers. Circulation 1996; 94: 19-25.

28. Davì G, Alessandrini $P$, Mezzetti $A$, et al. In vivo formation of 8-epi-PGF2alpha is increased in hypercholesterolemia. Arterioscler Thromb Vasc Biol 1997; 17: 3230-5.

29. Reilly MP, Delanty N, Tremoli E, et al. Increased formation of distinct F2 isoprostanes in hypercholesterolemia. Circulation 1998; 98: 2822-8.

30. Delanty N, Reilly M, Praticò D, et al. 8-Epi-PGF2alpha generation during coronary reperfusion: a potentia quantitative marker of oxidant stress in vivo. Circulation 1997; 96: 2492-9.

31. Reilly MP, Delanty N, O'Callaghan P, et al. Increased generation of the F2 isoprostanes, IPF2alpha-1 and 8-isoPGF2alpha, in acute coronary angioplasty: evidence for oxidant stress during coronary reperfusion in humans. Circulation 1997; 96: 3314-20.

32. Cipollone F, Ciabattoni G, Patrignani P, et al. Oxidant stress and aspirin-insensitive thromboxane biosynthesis in severe unstable angina. Circulation 2000; 102: 1007-13.

33. Lordkipanidzé M, Diodati JG, Turgeon J, Schampaert E, Palisaitis DA, Pharand C. Platelet count, not oxidative stress, may contribute to inadequate platelet inhibition by aspirin. Int J Cardiol 2010; 143: 43-50.

34. Wang LH, Hajibeigi A, Xu XM, Loose-Mitchell D, Wu KK. Characterization of the promoter of human prostaglandin $\mathrm{H}$ synthase-1 gene. Biochem Biophys Res Commun 1993 190: 406-11.

35. Halushka MK, Walker LP, Halushka PV. Genetic variation in cyclooxygenase 1: effects on response to aspirin. Clin Pharmacol Ther 2003; 73: 122-30.

36. Hillarp A, Palmqvist B, Lethagen S, Villoutreix BO, Mattiasson I. Mutations within the cyclooxygenase-1 gene in aspirin non-responders with recurrence of stroke. Thromb Res 2003; 112: 275-83.

37. Ulrich CM, Bigler J, Sibert J, et al. Cyclooxygenase 1 (COX1) polymorphisms in African-American and Caucasian populations. Hum Mutat 2002; 20: 409-10.

38. Rosiak M, Postula M, Kaplon-Cieslicka A, et al. The effect of doubling the dose of ASA versus switching to clopidogrel on platelet reactivity in patients with type 2 diabetes with high-on-treatment platelet reactivity: the AVOCADO study. Kardiol Pol 2013; in press, DOI: 10.5603/KP.2013.0056

39. Patrono C, Ciabattoni G, Pinca E, et al. Low dose aspirin and inhibition of thromboxane B2 production in healthy subjects. Thromb Res 1980; 17: 317-27.

40. Ciabattoni G, Pugliese F, Davi G, Pierucci A, Simonetti BM, Patrono C. Fractional conversion of thromboxane B2 to urinary 11-dehydrothromboxane B2 in man. Biochim Biophys Acta 1989; 992: 66-70.
41. Helmersson J, Arnlov J, Axelsson T, Basu S. A polymorphism in the cyclooxygenase 1 gene is associated with decreased inflammatory prostaglandin F2alpha formation and lower risk of cardiovascular disease. Prostaglandins Leukot Essent Fatty Acids 2009; 80: 51-6.

42. Lee CR, Bottone FG Jr, Krahn JM, et al. Identification and functional characterization of polymorphisms in human cyclooxygenase-1 (PTGS1). Pharmacogenet Genomics 2007; 17: 145-60.

43. Gonzalez-Conejero R, Rivera J, Corral J, Acuna C, Guerrero JA, Vicente V. Biological assessment of aspirin efficacy on healthy individuals: heterogeneous response or aspirin failure? Stroke 2005; 36: 276-80.

44. Lepantalo A, Mikkelsson J, Resendiz JC, et al. Polymorphisms of COX-1 and GPVI associate with the antiplatelet effect of aspirin in coronary artery disease patients. Thromb Haemost 2006; 95: 253-9. 